\title{
Optimal Securitization with Moral Hazard *
}

\author{
Barney Hartman-Glaser \\ UC Berkeley Haas \\ bhglaser@haas.berkeley.edu
}

\author{
Tomasz Piskorski \\ Columbia Business School \\ tp2252@columbia.edu
}

\author{
Alexei Tchistyi \\ UC Berkeley Haas \\ tchistyi@haas.berkeley.edu
}

\begin{abstract}
This paper considers the optimal design of mortgage backed securities (MBS) in a moral hazard setting with dynamic cash flows. A mortgage underwriter can engage in costly effort to screen for low risk borrowers and can sell loans to a secondary market. Potential investors cannot observe the effort of the mortgage underwriter. We find the optimal security design makes all transfers from investors to the underwriter contingent upon the time of first default. This design admits a straightforward implementation using a credit default swap (CDS) and a risk free bond. We then extend our model to include constraints to limit the loss faced by the underwriter for an early first default. In this more complicated setting, a simple implementation using a CDS and a risk free bond persists.
\end{abstract}

Keywords: Security design, mortgage backed securities, moral hazard.

${ }^{*}$ Preliminary and incomplete. We would like to thank Robert Anderson and Nancy Wallace for useful comments. All errors are our own. 


\section{Introduction}

Mortgage underwriters face a dilemma: either to invest in a costly screening effort to insure the quality of mortgages they underwrite or to relax the underwriting standards in order to save on the underwriting expenses. For example, the underwriter can try to collect as much information as possible about each mortgage applicant. Alternatively, the underwriter could collect no information at all and simply make loans to every mortgage applicant. Clearly, the second approach, while less costly in terms of the underwriting expenses, will result in higher default risks of associated with the underwritten mortgages.

Mortgage underwriters typically wish to sell their loans in a secondary market rather than hold loans in portfolio. Investors do not observe the underwriter's screening effort and, hence, the quality of the mortgages they are buying. Indeed, recent empirical work in Keys, Mukherjee, Seru, and Vig (2008) indicates that the process of securitization adversely affected the screening practices of subprime lenders. ${ }^{1}$ This naturally begs the question of how security design of mortgage backed securities (MBS) can address this agency problem.

To address this issue we consider an optimal contracting problem between a mortgage underwriter and secondary market investors. ${ }^{2}$ At the origination date, the underwriter can choose to undertake a costly effort that will result in low expected default rates of the underwritten mortgages. By selling loans, rather than holding them on the balance sheet, the mortgage underwriter can exploit new investment opportunities, i.e. make more loans. We model this feature by assuming that the underwriter is impatient, as in DeMarzo and Duffie (1999), i.e., the underwriter has a higher discount rate than the investors.

A moral hazard problem arises due to the fact that investors cannot observe the actions of the underwriter or the riskiness of the loans. However, the investors observe the default realizations of the underwritten mortgages. The default intensities can be either high or low depending on the underwriter's screening effort, and the payments from the investors

\footnotetext{
${ }^{1}$ For an good description of the market for securitized subprime loans, see Ashcraft and Schuermann (2009).

${ }^{2}$ Although we refer to the agent in our model as the underwriter we can think of this agent as any issuer of asset backed securities who must pay a cost to screen assets. For example, we could think of the issuer as an aggregator or arranger who purchases single loans from originators but can pay a cost to due diligence on the credit quality of the loans.
} 
to the underwriter can depend on them. We also assume that the underwriter has limited liability. The contracting objective is to find the optimal contract that implements the costly screening effort and also maximizes the expected payoff for the underwriter, provided the investors are making non-negative profits in expectation.

The optimal contract consists of a single lump sum transfer from the investors to the underwriter which takes place after an initial waiting period provided no default occurs. The intuition behind this contract is the following. By making the payment for mortgages contingent upon an initial period of no default, the investors can provide incentives for underwriters to screen for low risk mortgages since high risk mortgages will be more likely to default before the initial period is over. However, delaying payments past the initial waiting period is suboptimal since it does not exploit the difference in discount rates of the investors and the underwriter. Hence the optimal security design represents the balance of two forces. The first is that delaying payments and making them contingent on the performance of the loans provides incentives for the underwriter to engage in costly screening of borrowers. The second is that delaying payments to the underwriter is costly due to the underwriter's impatience.

We implement this contract using a credit default swap (CDS) and a risk free bond. The CDS is issued by the underwriter and is given to the investors who buy the pool of mortgages from the underwriter. The proceeds from the sale of the pool of mortgages are invested in the risk-free bond, which is held as a capital requirement for the CDS until it expires.

Interestingly, the optimal contract calls for the underwriter to pool mortgages and include a bundled derivative security in the sale. Alternatively, the underwriter could sell each mortgage individually and offer insurance on each one. We show that individual loan sale is suboptimal since it does not fully exploit the efficiency of paying the underwriter as quickly as possible while maintaining incentive compatibility.

One peculiar aspect of the optimal contract is that if a single mortgage defaults before the expiration of the CDS contract, the underwriter is paid nothing, while the investors keep the whole pool of mortgages. This may tempt the investors to accelerate defaults. In 
other words, by bribing a single borrower to default early the investors may acquire the entire pool of mortgages essentially for free. So, we extend our model to include constraints that limit the loss faced by the underwriter (and "gain" to the investors) in the event of an early default.

The optimal contract in this more complicated setting remains qualitatively similar to the original setting. Payment will still be in the form of lump sum transfers from the investors to the underwriter. However, now the transfers will depend on the entire history of defaults, not just the time of the first default. We also show that the optimal contract can be implemented using CDSs.

The rest of the paper proceeds as follows. Section 2 reviews the relevant literature. Section 3 present the basic model. Section 4 extends the basic model to include a novel constraint. Section 5 concludes.

\section{Literature Review}

The security design problem faced by an issuer of an asset backed security has its roots in the basic capital structure problem faced by a firm in the presence of asymmetric information as characterized by Myers and Majluf (1984). In such a setting firms try to minimize the mispricing of their offered securities. The classic "folklore" theorem states that securities can be ranked by their informational sensitivity in a "pecking order." In the context of asset backed securities it becomes less clear what exactly the ranking of securities should be, or if a well defined ranking even exists. Nachman and Noe (1994) present a rigorous frame work for when a given a security design minimizes mispricing due to asymmetric information.

Leland and Pyle (1977) (hereafter LP) and DeMarzo and Duffie (1999) (hereafter DD) present signaling models of security design and capital structure in which issuers face a lemons problem induced by private information about the distribution of cash flow. In the LP model an informed risk adverse entrepreneur wants to sell her firm to an investor. By retaining a portion of the firm the entrepreneur signals the quality of cash flows. In the DD model, the issuer of an asset backed security faces a downward slopping demand curve 
but faces retention costs due to other investment opportunities. Accordingly, she chooses to issue a security that balances the cost of retention with illiquidity. The basic intuition in both of these models is that in the presence of asymmetric information, the issuer of a security can benefit by creating and selling a security that is less informationally sensitive and retaining the residual which is more informational sensitive. This idea underlies much of the literature on asset backed securities.

Boot and Thakor (1993) develops a rational expectations model in which information acquisition is profitable. The issuer creates two securities, one which is informationally insensitive and one which is not. This provides incentives to informed traders to enter the market. This model does not consider an informed issuer as the task of selling the assets is delegated to an uninformed intermediary.

Glaeser and Kallal (1997) (hereafter GK) present a setting in which the bundling of securities for resale can increase liquidity over individual sale. In their model, intermediaries can engage in costly information gathering over multiple assets and bundling reduces the probability that the pool of assets will take on extreme values and hence increases liquidity. Moreover, they show that when markets are intrinsically illiquid adding more information to the market, by selling assets individually for example, can actually further reduce liquidity.

Riddiough (1997) discusses the optimal design of asset backed securities when sellers have private information about asset value and thus face a lemons marketing problem. As in the LP and DD models, optimal security design creates a mix of securities which allows the seller to internalize the lemons problem. When the seller faces a capital requirement, she may not be able to fully internalize the lemons problem and hence must issue some informationally risky securities. Moreover, pooling assets that are not perfectly correlated can provide diversification benefits which can reduce lemons costs. This point is similar to GK in that pooling assets affects the distribution of payoffs to reduce the severity of the asymmetric information costs.

DeMarzo (2005) explains the structure of ABS by examining the balance of two forces. The first force is the information destruction effect of pooling, whereby selling bundled assets reduces value of information by limiting the issuers ability to use that information 
differently for different assets. The second force is the risk diversification effect whereby an issuer can create a low risk security from a large pool. As the number of assets grows large the latter effect dominates the former and informed intermediaries benefit from tranching and pooling. The author goes on to study the case of an uninformed issuer wishing to sell assets to a potentially informed intermediary. In this case, the uninformed issuer first sells assets in a pool to guard herself against underpricing, then the informed intermediary creates a low risk security from the pool to increase the return to information.

Axelson (2007) considers a setting in which investors have superior information about the distribution asset cash flows. The author gives conditions for which pooling may be an optimal response to investor private information and for which single asset sale is preferred.

In the literature on security design and ABS presented above the cash flows from assets are static. The possible exception is the GK model in which the issuer can release information after a delay, however this delayed information revelation can be essentially be viewed as a static measure of liquidity. In contrast to previous static models, we take a different approach by modeling mortgages with dynamic cash flows. Doing so increases the space of admissible securities and allows us to make predictions about the dynamics of the optimal security design.

Another important difference is that previous models do not explicitly consider moral hazard in underwriting practices. Although some of the previous models consider costly information acquisition, they do not explicitly model costly action taken by issuers. Such a moral hazard problem is likely to be important in private securitization markets where both the quality of assets and the operations of issuers are extremely difficult to verify. Indeed, some empirical studies, such as Mian and Sufi (2009), suggest that "mispriced agency conflicts" may have played a crucial role in the current mortgage crisis. In addition, evidence presented in Keys, Mukherjee, Seru, and Vig (2008) suggests that securitization of subrpime loans led to lax lender standards, especially when there is "soft" information about borrowers which determines default risk but is not easily verifiable by investors. 


\section{The Model}

\subsection{The general setup}

Time is infinite, continuous, and indexed by $t$. A risk neutral agent (the underwriter ${ }^{3}$ ) originates $N$ assets that she wants sell to a risk neutral principal (the investors) immediately after origination. The underwriter has the constant discount rate of $\gamma$ and the investors have the constant discount rate of $r$. We assume $\gamma>r$ to motivate trade.

The underwriter may undertake an action $e \in\{0,1\}$ at cost $c(N) e$ at the origination ( $\mathrm{t}$ $=0)$ of the pool of mortgages. This action is non-verifiable and hidden from the investors. Each asset generates constant cash $u$ until default which occurs according to an exponential random variable with parameter $\lambda \in\left\{\lambda_{H}, \lambda_{L}\right\}$ such that $\lambda=\lambda_{L}$ if $e=1$ and $\lambda=\lambda_{H}$ if $e=0$ and $\lambda_{H}>\lambda_{L}$. All defaults are mutually independent. After, default all assets have cash flow $0 .{ }^{4}$ We can think of this action as acquisition of information about the mortgages which affects their risk.

A contract consists of transfers from the investors to the issuer. We denote a contract by a family of $N+1$ functions $\left\{x_{n}\right\}_{n=0}^{N}$ such that $x_{0}(t)$ is the transfer at time $t$ given no default has occurred by time $t$ and $x_{n}\left(t, \ldots, \tau_{n}\right)$ for $1 \leq n \leq N$ is the cash flow at time $t$ from the investors to the underwriter given $\tau_{k}$ is the arrival time of the $k$ th default defined by

$$
\tau_{k}=\inf \left\{t \geq \tau_{k-1} \mid \text { a default occurs at } t\right\}
$$

for $1 \leq k \leq N$. Let $\tau_{N+1}=\infty$ for notational convenience. We impose limited liability so that $x_{n} \geq 0$ for all $n$. This contract space allows transfers from the agent to the principal to depend arbitrarily on the history of defaults up to the limited liability constraint. We will often use the terms contract and security design interchangeable in the following analysis. By using the term contract we simply mean a rule for assigning transfers given a history of

\footnotetext{
${ }^{3}$ Although we refer to the agent in our model as the underwriter, our setting applies equally well to other actors than mortgage underwriters. The defining characteristic of the agent in our model is that she can undertake costly hidden action to screen out high risk mortgages or assets

${ }^{4}$ The assumption that the assets pay 0 after default does not play a role in the contracting problem and is made for convenience only. The optimal contract will be the same for none zero recovery rates up to the promised value of the underwriter.
} 
defaults. For now we assume that it is efficient for the investors to provide incentives to the underwriter to choose $e=1$. To provide such incentives, we require the following constraint

$$
\begin{aligned}
E\left[\int_{0}^{\tau_{1}} e^{-\gamma t} x_{0}(t) d t\right. & \left.+\sum_{n=1}^{N} \int_{\tau_{n}}^{\tau_{n+1}} e^{-\gamma t} x_{n}\left(t, \tau_{1}, \ldots, \tau_{n}\right) d t \mid e=1\right]-c(N) \geq \\
E & {\left[\int_{0}^{\tau_{1}} e^{-\gamma t} x_{0}(t) d t+\sum_{n=1}^{N} \int_{\tau_{n}}^{\tau_{n+1}} e^{-\gamma t} x_{n}\left(t, \tau_{1}, \ldots, \tau_{n}\right) d t \mid e=0\right] . }
\end{aligned}
$$

Constraint (2) simply states that the expected payment given the high effort choice less the cost of effort must be greater than the expected payment given low effort.

In addition the underwriter must receive at least some promised utility $a_{0}(N)$ from the contract. If the market for underwriters is perfectly competitive, then the underwriter does not receive any of the surplus created by selling the assets. In this case, the underwriter's promised utility must be equal to the value she places on holding the $N$ assets. Since the assets are mutually independent we have

$$
a_{0}(N)=N E\left[\int_{0}^{\tau} e^{-\gamma t} u d t\right]-c(N)=N \frac{u}{\lambda_{L}+\gamma}-c(N)
$$

where $\tau$ is an exponential random variable with intensity $\lambda_{L}$. If however the underwriter has some market power, then $a_{0}(N)$ will exceed the value given in (3). To guarantee the underwriter receives her promised utility, we must have the following promise keeping constraint constraint

$$
\left.a_{0}(N) \leq E\left[\int_{0}^{\tau_{1}} e^{-\gamma t} x_{0}(t) d t+\sum_{n=1}^{N} \int_{\tau_{n}}^{\tau_{n+1}} e^{-\gamma t} x_{n}\left(t, \tau_{1}, \ldots, \tau_{n}\right)\right) d t \mid e=1\right]-c(N)
$$

which states that the the expected payment given the high effort less the cost of effort must be greater than or equal to the promised utility of the underwriter. We call a contract incentive compatible if it satisfies constraints (2) and (4).

The investors' problem is to maximize profits subject to providing incentives to expend effort and delivering a certain promised level of utility to the underwriter. Once we restrict our attention to incentive compatible contracts, the value the investors place on holding 
the assets is fixed since the contract cannot affect the distribution of mortgage cash flows other than to guarantee that the underwriter only originates low risk mortgages. Hence, the investors maximize profits by choosing the incentive compatible contract with the lowest expected cost under their discount rate. In other words, the investor chooses the least costly incentive compatible contract. We state this formally in the following definition.

Definition 1 Given a promised utility $a_{0}(N)$ to the underwriter, a contract $\left\{x_{n}\right\}_{n=0}^{N}$ is optimal if it solves the following problem

$$
b\left(a_{0}(N)\right)=\min _{\left\{x_{n}\right\} \geq 0} E\left[\sum_{n=0}^{N} \int_{\tau_{n}}^{\tau_{n+1}} e^{-r t} x_{n}\left(t, \tau_{n}\right) d t \mid e=1\right]
$$

such that

$$
\begin{gathered}
E\left[\int_{0}^{\tau_{1}} e^{-\gamma t} x_{0}(t) d t+\sum_{n=1}^{N} \int_{\tau_{n}}^{\tau_{n+1}} e^{-\gamma t} x_{n}\left(t, \tau_{1}, \ldots, \tau_{n}\right) d t \mid e=1\right]-c(N) \geq \\
E\left[\int_{0}^{\tau_{1}} e^{-\gamma t} x_{0}(t) d t+\sum_{n=1}^{N} \int_{\tau_{n}}^{\tau_{n+1}} e^{-\gamma t} x_{n}\left(t, \tau_{1}, \ldots, \tau_{n}\right) d t \mid e=0\right] \\
\left.a_{0}(N) \leq E\left[\int_{0}^{\tau_{1}} e^{-\gamma t} x_{0}(t) d t+\sum_{n=1}^{N} \int_{\tau_{n}}^{\tau_{n+1}} e^{-\gamma t} x_{n}\left(t, \tau_{1}, \ldots, \tau_{n}\right)\right) d t \mid e=1\right]-c(N) .
\end{gathered}
$$

It is important to note that Definition 1 is equivalent to a definition where we hold the cost to the investor fixed and maximize the utility of the underwriter. As an alternative to Definition 1, we could fix the cost paid by the investor $b(N)$ and find the contract which maximizes the underwriters initial utility $a_{0}(N)$. In the analysis that follows, we will find a one-to-one relationship between the cost paid by the investors and the value delivered to the underwriter; for any level of initial promised utility of the underwriter, we know the cost paid by the investors under the optimal contract and vice versa. Accordingly, we can form the set of supportable allocations of utility and costs

$$
\mathcal{B}_{N}=\left\{\left(a_{0}(N), b\left(a_{0}(n)\right)\right) \mid b\left(a_{0}(N)\right) \text { solves }(5)-(7) \text { given } a_{0}(N)\right\} .
$$


Each point in $\mathcal{B}_{N}$ represent an allocation of utility and costs is are supported by an optimal contract as defined above.

Both parties are risk neutral and no new information is revealed after the last default, hence it can never be optimal to have transfers from the investors to the underwriter after the last default due to the inefficiency of delaying transfers. We state this result as the following lemma.

Lemma 1 The optimal contract always has $x_{N} \equiv 0$.

Proof Follows directly from the fact that no new information is revealed after $\tau_{N}$ and the fact that $\gamma>r$.

Lemma (1) allows us to restrict our attention to specifying transfers that occur before the last default.

\subsection{The case of $N=2$}

We start by solving for the optimal contract when $N=2$. This base case provides the basic intuition we will use throughout our solution. By Lemma 1, we can restrict our attention to contracts with $x_{2} \equiv 0$. Evaluating expectations, Problem (5) now becomes

$$
\min _{x_{0}(t), x_{1}\left(\tau_{1}, t\right) \geq 0}\left[\begin{array}{c}
\int_{0}^{\infty} e^{-\left(r+2 \lambda_{L}\right) t} x_{0}(t) d t \\
+2 \int_{0}^{\infty} \lambda_{L} e^{-\lambda_{L} \tau_{1}} \int_{\tau_{1}}^{\infty} e^{-\left(r+\lambda_{L}\right) t} x_{1}\left(t, \tau_{1}\right) d t d \tau_{1}
\end{array}\right]
$$

subject to

$$
\left[\begin{array}{c}
\int_{0}^{\infty} e^{-\left(\gamma+2 \lambda_{L}\right) t} x_{0}(t) d t \\
+2 \int_{0}^{\infty} \lambda_{L} e^{-\lambda_{L} \tau_{1}} \int_{\tau_{1}}^{\infty} e^{-\left(\gamma+\lambda_{L}\right) t} x_{1}\left(t, \tau_{1}\right) d t d \tau_{1}
\end{array}\right] \geq a_{0}(2)+c(2) \quad(\mathrm{PC})
$$




$$
\begin{gathered}
{\left[\begin{array}{c}
\int_{0}^{\infty} e^{-\left(\gamma+2 \lambda_{H}\right) t} x_{0}(t) d t \\
+2 \int_{0}^{\infty} \lambda_{H} e^{-\lambda_{H} \tau_{1}} \int_{\tau_{1}}^{\infty} e^{-\left(\gamma+\lambda_{H}\right) t} x_{1}\left(\tau_{1}, t\right) d t d \tau_{1}
\end{array}\right]+c(2) \quad(\mathrm{IC})} \\
-\left[\begin{array}{c}
\infty \\
+2 \int_{0}^{\infty} \lambda_{L} e^{-\lambda_{L} \tau_{1}} \int_{\tau_{1}}^{\infty} e^{-\left(\gamma+2 \lambda_{L}\right) t} x_{0}(t) d t
\end{array}\right] \leq 0
\end{gathered}
$$

Problem (9)-(11)states that the investors minimize the sum of the expected present value payments before and after the first default to the underwriter subject to promise keeping and incentive compatibility constraints. We state the solution to Problem (9)-(11) in the following proposition.

Proposition 1 The optimal contract for $N=2$ has $x_{0}(t)=\delta\left(t-t_{0}\right) e^{\left(\gamma+2 \lambda_{L}\right) t_{0}}(a+c(2))$ and $x_{1}\left(\tau_{1}, t\right)=x_{2}\left(\tau_{1}, t\right)=0$, where

$$
t_{0}=\frac{1}{2\left(\lambda_{H}-\lambda_{L}\right)} \log \left(\frac{a_{0}(2)+c(2)}{a_{0}(2)}\right)
$$

and $\delta(\cdot)$ is the delta function such that

$$
\int_{0}^{\infty} \delta(s-t) f(s) d s=f(t)
$$

for any $f(t)$.

Proof Sketch For complete proof see the Appendix. After verifying that the proposed contract is indeed incentive compatible, the essential part of this proof comes down to finding the following inequality

$$
\frac{1}{a_{0}+c}\left[\int_{0}^{\infty} t e^{-\left(\gamma+2 \lambda_{L}\right) t} x_{0}(t) d t+2 \lambda_{L} \int_{0}^{\infty} \int_{\tau_{1}}^{\infty} t e^{-\gamma(t)} e^{-\lambda_{L}\left(t+\tau_{1}\right)} x_{1}\left(\tau_{1}, t\right) d t d \tau_{1}\right] \geq t_{0}
$$

which puts a lower bound on the risk adjusted duration of any incentive compatible contract. Once we have this inequality in hand, we can use the convexity of the exponential function 
to put put a lower bound on the cost of an incentive compatible contract. We can then show that the proposed contract achieves this lower bound and hence must be optimal.

The intuition behind the proof of Proposition 1 is the following. On the one hand, delaying payment is costly due to the difference in discount rates of the underwriter and investors. On the other hand, accelerating payment decreases the sensitivity of payments to the underwriter's choice of effort. These two forces imply that the optimal contract should feature the most accelerated payment structure that preserves the minimum sensitivity to effort choice needed to provide incentives. Inequality (12) summarizes this point by showing that the minimum duration (with respect to the risk adjusted discount rate) of any incentive compatible contract is exactly $t_{0}$, which turns out to be the duration of the optimal contract. Hence, the proof of Proposition 1 shows that optimal contracting problem we consider comes down to a duration minimization problem.

In order to find the minimum duration contract we note we can always improve on an arbitrary incentive compatible contract by delaying payment that occurs before $t_{0}$ and accelerating payment that occurs after $t_{0}$ until all payment occurs at $t_{0}$. Doing so reduces the duration of the contract. Eventually we will have all payment occurring at time $t_{0}$. The resulting contract is the optimal contract stated in Proposition 1.

The structure of the optimal contract is thus the following. The investors receive the entire pool of assets from the underwriter at time 0. In exchange for the pool of assets, investors give the underwriter a security which pays $\left(a_{0}(2)+c(2)\right) e^{\left(\gamma+2 \lambda_{L}\right) t_{0}}$ at time $t_{0}=$ $\frac{\log \left(a_{0}(2)+c(2)\right)-\log \left(a_{0}(2)\right)}{2\left(\lambda_{H}-\lambda_{L}\right)}$ conditional on no default occurring up to that point.

\subsection{The case of arbitrary $N$}

The basic intuition underlying the optimal contract for two mortgages generalizes to the case of an arbitrary number of assets. The optimal contracting problem again amounts to finding the minimum duration contract which provides the correct incentives to the underwriter. We formalize this result in the following proposition.

Proposition 2 The optimal contract has $x_{0}(t)=\delta\left(t-t_{0}\right) e^{\left(\gamma+N \lambda_{L}\right) t_{0}}\left(a_{0}(N)+c(N)\right)$ and 
$x_{n} \equiv 0$ for all $n \geq 1$, where

$$
t_{0}=\frac{1}{N\left(\lambda_{H}-\lambda_{L}\right)} \log \left(\frac{a_{0}(N)+c(N)}{a_{0}(N)}\right)
$$

and $\delta(\cdot)$ is the delta function such that

$$
\int_{0}^{\infty} \delta(s-t) f(s) d s=f(t)
$$

for any $f(t)$. Moreover

$$
b_{0}(a(N))=\left(\frac{a_{0}(N)+c(N)}{a_{0}(N)}\right)^{\frac{\gamma-r}{N\left(\lambda_{H}-\lambda_{L}\right)}}\left(a_{0}(N)+c(N)\right)
$$

Proof Sketch First note that the proposed contract is indeed incentive compatible by the same arguments given for the case with 2 mortgages. The key aspect of the previous proof which we must change is inequality (12). Let $t_{0}=\frac{1}{N\left(\lambda_{H}-\lambda_{L}\right)} \log \left(\frac{a_{0}(N)+c(N)}{a_{0}(N)}\right)$. With some algebra it can be shown that for the case of $N$ assets we have the following inequality

$\frac{1}{a_{0}(n)+c(N)}\left[\sum_{n=1}^{N-1} \frac{N ! \lambda_{L}^{n}}{(N-n) !} \int_{\mathcal{R}_{n}} t \exp \left(-\left(\gamma+(N-n) \lambda_{L}\right) t-\lambda_{L} \sum_{i=1}^{n} \tau_{n}\right) x_{n}\left(t, \tau_{1}, \ldots, \tau_{n}\right) d \mathcal{A}_{n}\right] \geq t_{0}$.

where

$$
\begin{aligned}
\mathcal{R}_{n} & =(0, \infty) \times\left(\tau_{1}, \infty\right) \times \cdots \times\left(\tau_{n}, \infty\right) \\
d \mathcal{A}_{n} & =d t d \tau_{n} \cdots d \tau_{1}
\end{aligned}
$$

Inequality (14) states that the minimum (risk-adjusted) duration achieved by any incentive compatible contract is $t_{0}$, which is of course the duration of the proposed contract. We can use this fact to show that the proposed contract is indeed optimal with similar arguments as in the case of 2 assets. 
Proposition 2 states that the optimal contract still makes all transfers contingent on the time of first default. The fact that adding additional assets does not mean that the optimal contract is contingent on more than just the time of first default is perhaps surprising. Indeed it would seem that when the number of assets in the pool goes up, we could improve upon the efficiency of the contract by making it contingent on the times of subsequent defaults. The key insight which renders this intuition false is that any contracting featuring payment after the time of first default necessarily delays payment relative to the optimal contract.

The contract follows from the classic Principal-Agent intuition. The investors act as if they are performing inference on the action of the underwriter given the history of default events. Consider the following likelihood ratio

$$
\mathcal{L}(t)=\frac{P\left(e=0 \mid \tau_{1}>t\right)}{P\left(e=1 \mid \tau_{1}>t\right)}=\frac{e^{-N \lambda_{H} t}}{e^{-N \lambda_{L} t}}=e^{-N\left(\lambda_{H}-\lambda_{L}\right) t}
$$

Transfer from the investors to the underwriter takes place when this likelihood ratio reaches a lower threshold, i.e. when the investor can be reasonable confident that the true default intensity is $\lambda_{L}$. It should be noted that this threshold $\mathcal{L}\left(t_{0}\right)=\frac{a_{0}(N)}{a_{0}(N)+c(N)}$ only depends on $N$ through the promised value of the underwriter and her effort costs.

\subsection{Implementation}

The structure of the optimal contract seems odd at first glance since it calls for a lump sum transfer at date $t_{0}$ contingent on no defaults occurring prior to that date. However, this contract admits a natural implementation using commonly traded securities as we show in the following proposition.

Proposition 3 Let $A_{0}=\left(a_{0}(N)+c(N)\right) e^{-\left(\gamma+n \lambda_{L}\right) t_{0}}$, the optimal contract can be implemented as follows:

- At time $t=0$ the underwriter transfers the assets to the investors along with a credit derivative swap (CDS) on the time of first default of the pool of assets with a notional of $\frac{A_{0}\left(r+\lambda_{L}\right)}{u}$ and an expiration date of $t_{0}$. 
- At time $t=0$ the investors pays $A_{0}$ to the underwriter in the form of a risk free consul bond that pays interest at the rate $r$ which flows to the investors. The bond is used a capital requirement for the CDS contract and cannot be liquidated until after expiration.

Proof The proposed implementation yields the same net transfers as the optimal contract, so they are equivalent.

The implementation of the optimal contract given in Proposition 3 yields the following interpretation. The investors would like to pay the underwriter for the pool at time zero to exploit the difference in discount rates, but doing so would fail to provide incentives to the underwriter expend effort. In order to commit to high effort the underwriter sells insurance to the investors on the pool value at fair price given high effort. Due to limited liability constraints the underwriter cannot commit to having enough resources to cover the insurance if a default occurs before expiration, hence the proceeds from the sale of the bundled assets and insurance are placed in the risk free bond, the balance of which is transferred to the underwriter at the expiration of the CDS.

There are two key differences between this implementation and others found in the literature. The first difference is the roll pricing plays in the structure of the optimal contract. In previous research, such as DeMarzo (2005), issuers try to minimize mispricing due to a lemons problem. In our setting, the underwriter uses the price of the CDS as a commitment mechanism to exert effort. In other words, the underwriter is willing to sell the CDS at a fair price given high effort which is lower than the price of the CDS given low effort. The second difference is the dynamic nature of our contract which allows for the underwriter to provide insurance to the investors even though we maintain a limited liability constraint. In a static setting, the security issued by the underwriter would resemble pure debt. In our dynamic setting, the security design is instead made up of bundled debt and insurance. 


\subsection{Discussion}

Up to this point we have been fairly general about the cost of effort and the promised value that is delivered to the underwriter. What we have described so for is the set of supportable allocations $\mathcal{B}_{N}$. We now investigate a specific point in $\mathcal{B}_{N}$. Suppose that capital markets are perfectly competitive so that investors make zero profits as follows

$$
\underbrace{\left(\frac{a_{0}(N)+c(N)}{a_{0}(N)}\right)^{\frac{\gamma-r}{N\left(\lambda_{H}-\lambda_{L}\right)}}\left(a_{0}(N)+c(N)\right)}_{\text {Cost of Contract }}=\underbrace{N \frac{u}{r+\lambda_{L}}}_{\text {Present Value of Assets }} .
$$

Equation (16) points out that in the case of perfectly competitive capital markets, the promised value depends and both the number of assets in the pool and the cost structure of effort. Thus, the shape of the underwriter's promised utility with respect to the number of assets in the pool depends on the shape of the cost of effort with respect to the number of asset. In general we can't solve equation (16) for $a(N)$. Instead we offer a numerical examples shown in Figures 1 and 2 which plot the promised utility of the underwriter against the underwriter's value of holding the mortgages on portfolio.

We can see that when effort costs are convex, as in Figure 1, the promised value is a concave function of the number of assets in the pool. In fact, in this particular example, there exists a finite maximum for $a_{0}(N)$ which means there exists a finite optimal pool size when effort costs are convex, although the choice of $N$ is outside the model. Additionally, $a_{0}(N)$ is maximized for a larger $N$ than the underwriter places on holding the assets on portfolio. This suggests that when effort costs are convex, the underwriter will form larger assets pools when preparing assets for securitization than when planning to hold assets on portfolio. In contrast, as is shown in Figure 2, $a(n)$ is strictly increasing when effort costs exhibit increasing returns to scale.

Next, we explore how the nature of the contract varies with respect to the parameters of the model. Holding the number of assets constant and assuming that the promised value of the agent doe not depend on any parameters other than $N,{ }^{5}$ we investigate how changes

\footnotetext{
${ }^{5}$ This assumption is restrictive and can be relaxed. It holds for $\lambda_{H}$ if the market for underwriter's is
} 


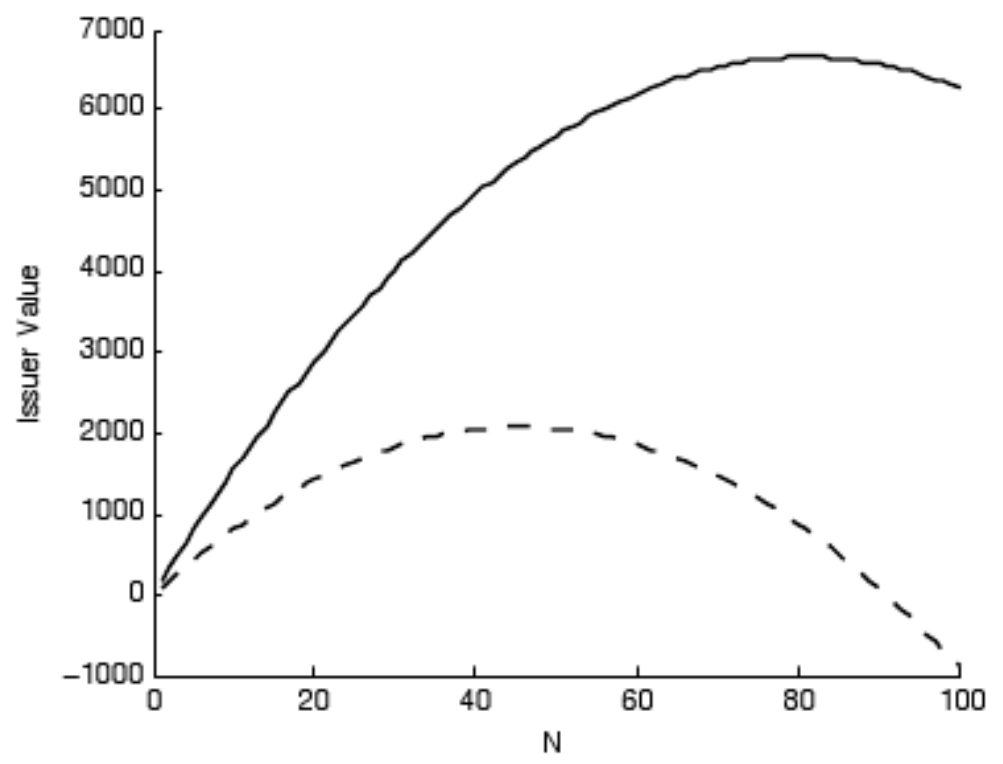

Figure 1: $a(N)$ versus the underwriter's value of holding the assets when effort exhibits decreasing returns to scale. The dashed curve is the underwriter's value for holding the assets in portfolio and the solid curve is her promised value from selling the assets. Parameter values: $u=10, L=.01, H=.03, r=.05, \gamma=.10$ and $c(N)=N^{2}$

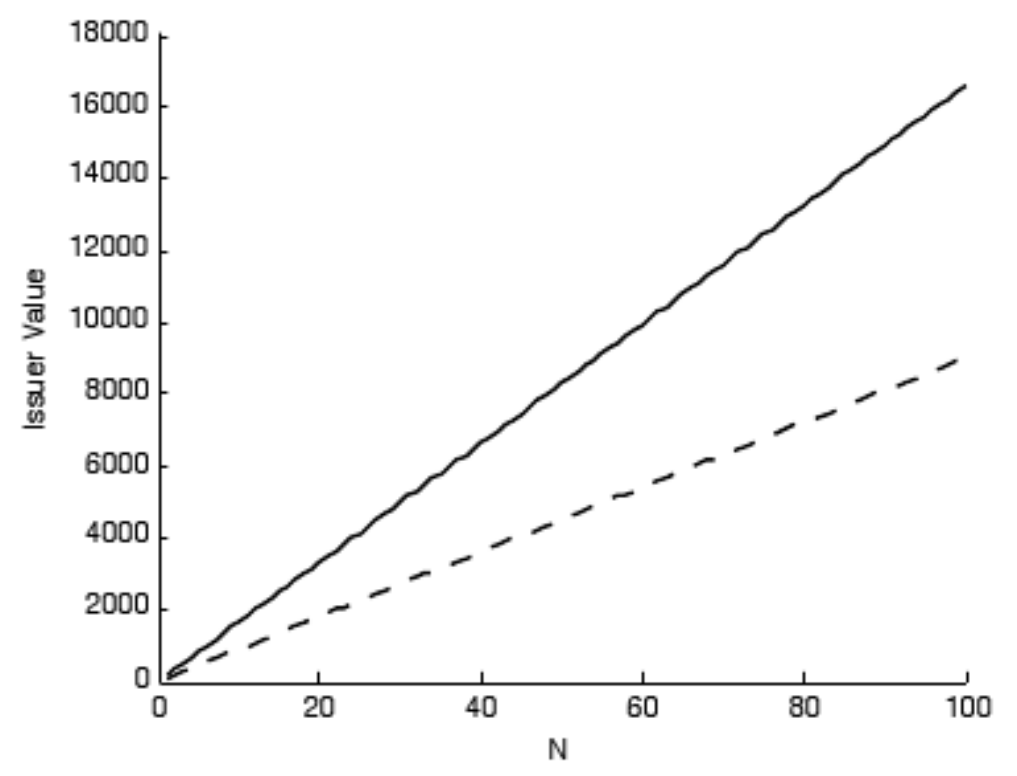

Figure 2: $a(N)$ versus the underwriter's value of holding the assets when effort exhibits increasing returns to scale. The dashed line is the underwriter's value for holding the assets in portfolio and the solid line is her promised value from selling the assets. Parameter values: $u=10, L=.01, H=.03, r=.05, \gamma=.10$ and $c(N)=10+N$ 
in the parameters governing risk and discounting affect the optimal contract.

First consider the difference $\Delta \lambda=\lambda_{H}-\lambda_{L}$ in risk of low risk and high risk assets. As $\Delta \lambda$ increases $t_{0}$ naturally decreases since

$$
\frac{\partial t_{0}}{\partial \Delta \lambda_{H}}=-\frac{1}{N(\Delta \lambda)^{2}} \log \left(\frac{a_{0}(N)+c(N)}{a_{0}(N)}\right)
$$

This occurs because if the difference in riskiness of the two asset classes is relatively larger, the inference problem faced by the underwriter is relatively smaller. This can be seen by examining the derivative of the likelihood ratio $\mathcal{L}$ of Equation $(15)$. We have

$$
\frac{d \mathcal{L}}{d \Delta \lambda}=-N \mathcal{L}
$$

hence for larger values of $N$, the likelihood ratio decreases more rapidly. Holding $\mathcal{L}\left(t_{0}\right)=$

$\frac{a_{0}(N)}{a_{0}(N)+c(N)}$ constant we get the the greater $\Delta \lambda$ the sooner the likelihood ratio will decrease to the lower threshold $\mathcal{L}_{0}$ and trigger payment.

Another feature of note is that the difference in the discount rates of the underwriter and investors plays no role in timing or payouts of the contract once the allocation of the surplus generated by asset transfer is fixed. This is because the discount rates play no role in the inference problem of the investors.

\subsection{Asset Pooling}

The underwriter is endowed with an all or nothing screening technology in our model. In practice, it may be the case that the underwriter could employ the technology for some of the mortgages and not all. With such a technology we would need separate incentive compatibility constraints for each mortgage. In other words, we would need to rule out all deviations that take the form in which the underwriter chooses not to apply effort to at least one loan. This amounts to a restriction on the space of incentive compatible contracts. It turns out that the contract spelled out in Proposition 2 satisfies these additional incentive compatibility constraints and hence must be optimal over the restricted space. This implies perfectly competitive. In that case $a(N)$ is given in equation (3) and does not depend on $\lambda_{H}$. 
the following important corollary to Proposition (2).

Corollary 1 For a given promised utility $a_{0}(N)$, pooling mortgages dominates individual asset sale.

The optimal contract depends only on the time of the first termination which means that any contract that depends on more information than the time of first default is necessarily suboptimal. In particular, selling assets individually in a way that preserves incentive compatibility would depend on the time of each default, and hence is suboptimal. Other results in the literature, for example DeMarzo (2005) or Glaeser and Kallal (1997), typically attribute pooling to minimizing mispricing through reducing the sensitivity of offered securities to private information. In our model, pooling is a consequence of providing incentives in the least costly manner.

\section{An additional constraint}

The contract we derived in section 3 depends entirely on the first default time creating the following less than desirable situation. If the loss faced by the investors of an early default is not too high and they have an ability to accelerate the time of first default, then in doing so the investors could acquire the entire pool of assets without paying anything to the underwriter. Hence the contract induces a benefit to the investors of a default for time $t_{0}$. In order to rule out such a benefit we would like to impose a constraint on the incentives of the investors to accelerate default. This would add greatly to the complexity of the problem and so we instead impose a constraint on the sensitively of the payoff to the underwriter to default. This constraint will proxy for the idea that investors should not stand to gain too much from the default of any given asset.

In this section we restrict our attention to the case of two assets for the sake of simplicity. Since we are only considering two assets, we suppress the dependence of $a_{0}(N)$ and $c(N)$ and $N$. We will add a constraint to Problem (9) that limits the loss faced by the underwriter at the time of first default. We will then solve this problem recursively, first solving the 
contracting problem after the first default given a level of utility to be delivered to the underwriter at the time of first default. Next, we find the optimal continuation utility to deliver to the underwriter at the time of first default conditional on effort. Finally we solve the optimal contracting problem before the time of first default. To that end, we introduce some new notation to ease exposition. Let $a(t)$ be the underwriter's expected present value at time $t$ for the remaining cash flow from the contract before the first default conditional on high effort. Similarly, let $a^{d}(t)$ and $\hat{a}^{d}(t)$ be the underwriter's expected present value at time $t$ for the remaining cash flow from the contract when a default occurs at time $t$ conditional on high and low effort respectively. With this new notation we can represent a contract with the triple $\left(x_{0}(t), a^{d}(t), \hat{a}^{d}(t)\right)^{6}$ where $x_{0}(t)$ is the time $t$ transfer from the investors to the underwriter conditional on no default up to time $t$, and $a^{d}(t)$ and $\hat{a}^{d}(t)$, are the promised remaining values of the contract conditional on default at time $t$. Let $b\left(a_{0}, 2\right)$ be the cost paid by the investors given a promised utility for the underwriter and $b\left(a^{d}(t), \hat{a}(t)^{d}, 1\right)$ be the cost paid by the investors when delivering a promised remaining value of $a^{d}(t)$ for high effort and $\hat{a}^{d}(t)$ for low effort, conditional on the first default occurring at time $t$. We have the following definition of the optimal contract.

Definition 2 Given an promised utility $a_{0}$ for the underwriter, a contract $\left(x_{0}(t), a^{d}(t), \hat{a}^{d}(t)\right)$ is optimal if it solves the following problem

$$
b\left(a_{0}, 2\right)=\min _{x_{0}(t), a^{d}(t), \hat{a}^{d}(t) \geq 0}\left\{\int_{0}^{\infty} e^{-\left(r+2 \lambda_{L}\right) t} x_{0}(t) d t+2 \lambda_{L} \int_{0}^{\infty} e^{-\left(r+2 \lambda_{L}\right) t} b\left(a^{d}(t), \hat{a}^{d}(t), 1\right) d t\right\}
$$

\footnotetext{
${ }^{6}$ Although effort is still unobservable, for any contract $\left(x_{0}(t), x_{1}\left(\tau_{1}, t\right)\right)$ we can always calculate the remaining value of the contract at the time of first default as

$$
a^{d}\left(\tau_{1}\right)=\int_{0}^{\infty} e^{-\left(\gamma+\lambda_{L}\right) s} x_{1}\left(\tau_{1}, s\right) d s, \hat{a}^{d}\left(\tau_{1}\right)=\int_{0}^{\infty} e^{-\left(\gamma+\lambda_{H}\right) s} x_{1}\left(\tau_{1}, s\right) d s
$$
}


such that

$$
\begin{aligned}
a_{0}+c & \leq \int_{0}^{\infty} e^{-\left(\gamma+2 \lambda_{L}\right) t} x_{0}(t) d t+2 \lambda_{L} \int_{0}^{\infty} e^{-\left(\gamma+2 \lambda_{L}\right) t} a^{d}(t) d t \\
a_{0} & \geq \int_{0}^{\infty} e^{-\left(\gamma+2 \lambda_{H}\right) t} x_{0}(t) d t+2 \lambda_{H} \int_{0}^{\infty} e^{-\left(\gamma+2 \lambda_{H}\right) t} \hat{a}^{d}(t) d t \\
\frac{a^{d}(t)}{a(t)} & \geq q \text { for } q \in[0,1] \\
a(t) & =\int_{t}^{\infty} e^{-\left(\gamma+2 \lambda_{L}\right)(s-t)} x_{0}(s) d s+2 \lambda_{L} \int_{t}^{\infty} e^{-\left(\gamma+2 \lambda_{L}\right)(s-t)} a^{d}(s) d s
\end{aligned}
$$

where

$$
\begin{aligned}
b\left(a^{d}(t), \hat{a}^{d}(t), 1\right) & =\min _{x_{1}(t) \geq 0} \int_{0}^{\infty} e^{-\left(r+\lambda_{L}\right) s} x(s) d s \\
\text { such that } & \\
a^{d}(t) & =\int_{0}^{\infty} e^{-\left(\gamma+\lambda_{L}\right) t} x_{1}(t, s) d s \\
\hat{a}^{d}(t) & =\int_{0}^{\infty} e^{-\left(\gamma+\lambda_{H}\right) t} x_{1}(t, s) d s .
\end{aligned}
$$

The only difference between Problem (9) and Problem (19) is the addition of constraint (22) which guarantee's that the underwriter's continuation value of the contract cannot be reduced by more than a factor of $q .^{7}$. Indeed, Problem (9) is equivalent to Problem (19) for $q=0$. It is important to note that although the underwriter's moral hazard problem remains static, we now have a dynamic constraint given by (22).

Note the we have solved problem (24) in Proposition 2. Indeed we found that

$$
b\left(a^{d}(t), \hat{a}^{d}(t), 1\right)=\left(\frac{a^{d}(t)}{\hat{a}^{d}(t)}\right)^{\frac{\gamma-r}{\lambda_{H}-\lambda}} a^{d}(t)
$$

and

$$
x_{1}\left(t, \tau_{1}\right)=\delta\left(t-t_{1}\left(\tau_{1}\right)\right) e^{\left(\gamma+\lambda_{L}\right)\left(t_{1}\left(\tau_{1}\right)-t\right)} a^{d}\left(\tau_{1}\right), t_{1}\left(\tau_{1}\right)=\tau_{1}+\frac{1}{\lambda_{L}-\lambda_{H}} \log \left(\frac{\hat{a}^{d}(t)}{a^{d}(t)}\right) .
$$

\footnotetext{
${ }^{7}$ We could have used a linear constraint of the form $a(t)-a^{d}(t) \leq q$ to capture the same idea. However such a constraint makes the problem considerably less tractable since it necessarily cannot bind for values of $a(t)<q$. Thus we would have a constraint which may bind at some times and not others.
} 
where $\delta(\cdot)$ is the delta function. After the first default, the problem is identical to the original contracting problem with one asset, with the exception that contract now delivers $a^{d}(t)$ for high effort $\hat{a}^{d}(t)$ for low effort conditional on the first default occurring at time $t$. Recall that in the previous section, after the first default the the underwriter receives zero.

The main intuition behind the solution of Problem (9) should persist in this new problem. Namely, the optimal contract will still be the minimum duration contract which provides incentives, however we must now satisfy constraint (22) as well. We will take the following approach, first we will assume that all the constraints must bind. Next, we will simplify the problem somewhat by first solving for $a(t)$ and $\hat{a}(t)$ in terms of $x_{0}(t)$. Finally we will take a first order approach to the help us guess the solution, which we will then verify in the appendix.

Before proceeding it is important to give some intuition for why constraints (20) - (22) should bind. Clearly constraint (20) should bind since delivering any utility above the minimum promised level of utility would be an added cost for the investors. Similarly, constraint (21) should bind since providing more incentives than the minimum amount necessary to induce effort increase the cost paid by the investor by increasing the duration of the contract. Lastly, if $a^{d}(t) / a(t)>q$ then more payment occurs after the first default than is required by constraint (22), which again increases the duration of the contract.

Once we assume that all constraints bind, we can substitute (20) into (23) and differentiate to get the following ordinary differential equation for $a(t)$

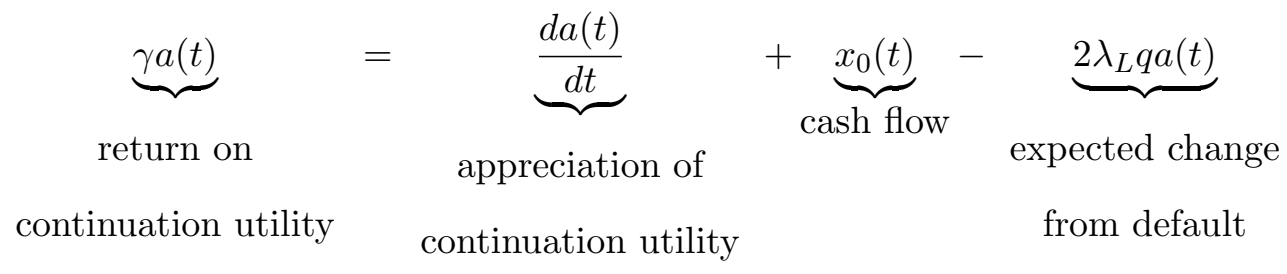

subject to the initial condition $a(0)=a_{0}+c$. The solution of $(29)$ is

$$
a(t)=\left(a_{0}+c\right) e^{\left(\gamma+2 \lambda_{L} q\right) t}-e^{\left(\gamma+2 \lambda_{L} q\right) t} \int_{0}^{t} e^{-\left(\gamma+2 \lambda_{L} q\right) s} x_{0}(s) d s
$$


which implies

$$
a^{d}(t)=q\left(a_{0}+c\right) e^{\left(\gamma+2 \lambda_{L} q\right) t}-q e^{\left(\gamma+2 \lambda_{L} q\right) t} \int_{0}^{t} e^{-\left(\gamma+2 \lambda_{L} q\right) s} x_{0}(s) d s
$$

Next we consider $\hat{a}^{d}(t)$. We have the following first order condition for $\hat{a}^{d}(t)$

$$
-2 \lambda_{L}\left(\frac{\gamma-r}{\lambda_{H}-\lambda_{L}}\right) e^{-\left(r+2 \lambda_{L}\right) s}\left(\frac{a^{d}(s)}{\hat{a}^{d}(s)}\right)^{1+\frac{\gamma-r}{\lambda_{H}-\lambda_{L}}}=-2 \lambda_{H} \alpha_{2} e^{-\left(\gamma+2 \lambda_{H}\right) s}
$$

where $\alpha_{2}$ is the multiplier on constraint (21). Inspection of (32) leads us to conjecture that an optimal contract must have $\hat{a}^{d}(t)=K_{2} e^{-K_{1} t} a^{d}(t)$ where $K_{2}$ and $K_{1}$ are constants. We formalize this in the following Lemma.

Lemma 2 For any contract $\left(x_{0}, a^{d}(t), \hat{a}^{d}(t)\right)$ which satisfies constraints (20) - (22), there exists a contract $\left(x_{0}, a^{d}(t), K_{2} e^{-K_{1} t} a^{d}(t)\right)$ which yields a weakly lower cost to the investors where

$$
K_{1}=\frac{\left((\gamma-r)+2\left(\lambda_{H}-\lambda_{L}\right)\right)\left(\lambda_{H}-\lambda_{L}\right)}{(\gamma-r)+\left(\lambda_{H}-\lambda_{L}\right)}
$$

and $K_{2} \geq 0^{6}$ is constant.

Proof See Appendix.

Note that Lemma 2 allows us to restrict our attention to contracts of the form $\left(x_{0}(t), a^{d}(t), K_{2} e^{-K_{1} t} a^{d}(t)\right)$ which greatly simplifies the analysis. Once we choose $x_{0}(t), a^{d}(t)$ and $\hat{a}^{d}(t)$ are given so Problem (19) reduces to finding the optimal $x_{0}(t)$.

We now proceed to find $x_{0}(t)$. Using what we have deduced about $a^{d}(t)$ and $\hat{a}^{d}(t)$ above we can rewrite Problem (19) as

$$
\begin{aligned}
& b\left(a_{0}, \hat{a}_{0}, 2\right)=\min _{x_{0}(t)}\left\{\int_{0}^{\infty} e^{-\left(r+2 \lambda_{L}\right) t} x_{0}(t) d t+\right. \\
& \left.2 \lambda_{L} \int_{0}^{\infty} e^{-\left(r+2 \lambda_{L}\right) t}\left(K_{2} e^{-K_{1} t}\right)^{-\frac{\gamma-r}{\lambda_{H}-\lambda_{L}}} e^{\left(\gamma+2 \lambda_{L} q\right) t}\left(q\left(a_{0}+c\right)-\int_{0}^{t} e^{-\left(\gamma+2 \lambda_{L} q\right) s} x_{0}(s) d s\right) d t\right\} .
\end{aligned}
$$


where $K_{1}$ is given in Lemma 2 , and

$K_{2}=\left(a_{0}-\int_{0}^{\infty} e^{-\left(\gamma+2 \lambda_{H}\right) t} x_{0}(t) d t\right)\left(2 \lambda_{H} \int_{0}^{\infty} e^{2 \lambda_{L}(q-1) t}\left(q\left(a_{0}+c\right)-\int_{0}^{t} e^{-\left(\gamma+2 \lambda_{L} q\right) t} x_{0}(s) d s\right) d t\right)^{-1}$

assuming all constraints bind.

We now state the main result of this section.

Proposition 4 The optimal contract has

$$
\begin{aligned}
& x_{0}(t)=\delta\left(t-t_{0}\right) y_{0} \\
& a^{d}(t)= \begin{cases}q\left(a_{0}+c\right) e^{\left(\gamma+2 \lambda_{L} q\right) t} & \text { for } t \leq t_{0} \\
0 & \text { for } t>t_{0}\end{cases} \\
& \hat{a}^{d}(t)=K_{2} e^{-K_{1} t} a^{d}(t)
\end{aligned}
$$

where $t_{0}$ and $y_{0}$ are to be defined.

Proof The method of proof will be similar to the proof of Proposition 1. We will find a duration-like inequality that puts a lower bound on the duration of the contract and then show the proposed contract achieves that lower bound.

\section{Conclusion}

This paper studies a model of asset securitization in a moral hazard setting with dynamic cash flows. We find that the optimal contract in our most simple setup is a lump sum payment from the investors to the underwriter conditional on a period of no defaults. We then go on to give a simple implementation of the contract using a risk free bond and a CDS. By bundling a CDS with the mortgage pool, the underwriter can in effect signal high effort by selling insurance which is priced fairly given high effort.

We then go on to include a constraint that limits the loss faced by the underwriter for an individual default. The qualitative features of the optimal security design remain the same in this more complicated setting. Namely, the optimal security design still calls for 
lump sum transfers from the investors to the underwriter contingent upon the history of default.

\section{A Appendix}

Proof of Proposition 1 We suppress the dependence of $a_{0}(N)$ and $c(N)$ on $N$ to ease notation. First observe that the proposed contract satisfies constraints (10) since

$$
\int_{0}^{\infty} e^{-\left(\gamma+2 \lambda_{L}\right) t} \delta\left(t-t_{0}\right) e^{\left(\gamma+2 \lambda_{L}\right) t_{0}}\left(a_{0}+c\right) d t=a_{0}+c .
$$

Next observe that the proposed contract satisfies constraint (11) since

$$
\begin{aligned}
\int_{0}^{\infty} e^{-\left(\gamma+2 \lambda_{H}\right) t} \delta\left(t-t_{0}\right) e^{\left(\gamma+2 \lambda_{L}\right) t_{0}}(a+c), d t & =e^{2\left(\lambda_{L}-\lambda_{H}\right) t_{0}}\left(a_{0}+c\right) \\
& =a_{0}
\end{aligned}
$$

Now suppose $\left(x_{0}(t), x_{1}\left(t, \tau_{1}\right)\right)$ is any contract which satisfies constraints (10) and (11). We have

$$
\int_{0}^{\infty} e^{-\left(\gamma+2 \lambda_{H}\right) t} x_{0}(t) d t=\int_{0}^{\infty} e^{2\left(\lambda_{L}-\lambda_{H}\right) t} e^{-\left(\gamma+2 \lambda_{L}\right) t} x_{0}(t)
$$

But $e^{2\left(\lambda_{L}-\lambda_{H}\right) t} \geq 2\left(\lambda_{L}-\lambda_{H}\right) e^{2\left(\lambda_{L}-\lambda_{H}\right) t_{0}}\left(t-t_{0}\right)+e^{2\left(\lambda_{L}-\lambda_{H}\right) t_{0}}$ since $e^{2\left(\lambda_{L}-\lambda_{H}\right) t}$ is convex, which together with (35) implies that

$$
\int_{0}^{\infty} e^{-\left(\gamma+2 \lambda_{H}\right) t} x_{0}(t) d t \geq e^{2\left(\lambda_{L}-\lambda_{H}\right) t_{0}} \int_{0}^{\infty}\left(2\left(\lambda_{L}-\lambda_{H}\right)\left(t-t_{0}\right)+1\right) e^{-\left(\gamma+\lambda_{L}\right) t} x_{0}(t) d t
$$

Next we have

$\int_{0}^{\infty} \lambda_{H} e^{-\lambda_{H} \tau_{1}} \int_{\tau_{1}}^{\infty} e^{-\left(\gamma+\lambda_{H}\right) t} x_{1}\left(\tau_{1}, t\right) d t d \tau_{1}=\lambda_{H} \int_{0}^{\infty} \int_{\tau_{1}}^{\infty} e^{-\gamma t} e^{-\lambda_{L}\left(t+\tau_{1}\right)} e^{\left(\lambda_{L}-\lambda_{H}\right)\left(t+\tau_{1}\right)} x_{1}\left(\tau_{1}, t\right) d t d \tau_{1}$

But $e^{\left(\lambda_{L}-\lambda_{H}\right)\left(t+\tau_{1}\right)} \geq\left(\lambda_{L}-\lambda_{H}\right) e^{2\left(\lambda_{L}-\lambda_{H}\right) t_{0}}\left(t+\tau_{1}-2 t_{0}\right)+e^{2\left(\lambda_{L}-\lambda_{H}\right) t_{0}}$ since $e^{\left(\lambda_{L}-\lambda_{H}\right)\left(t+\tau_{1}\right)}$ 
is convex in $t+\tau_{1}$, which together with (37) implies that

$$
\begin{aligned}
& \int_{0}^{\infty} \lambda_{H} e^{-\lambda_{H} \tau_{1}} \int_{\tau_{1}}^{\infty} e^{-\left(\gamma+\lambda_{H}\right) t} x_{1}\left(\tau_{1}, t\right) d t d \tau_{1} \geq \\
& \lambda_{L} e^{2\left(\lambda_{L}-\lambda_{H}\right) t_{0}} \int_{0}^{\infty} \int_{\tau_{1}}^{\infty} e^{-\gamma(t)} e^{-\lambda_{L}\left(t+\tau_{1}\right)}\left(\left(\lambda_{L}-\lambda_{H}\right)\left(t+\tau_{1}-2 t_{0}\right)+1\right) x_{1}\left(\tau_{1}, t\right) d t d \tau_{1}
\end{aligned}
$$

since $\lambda_{L}<\lambda_{H}$. We can combine inequalities (10), (11), (36), and (38) to get

$$
\begin{aligned}
a_{0} \geq & e^{2\left(\lambda_{L}-\lambda_{H}\right) t_{0}} \int_{0}^{\infty}\left(2\left(\lambda_{L}-\lambda_{H}\right)\left(t-t_{0}\right)+1\right) e^{-\left(\gamma+\lambda_{L}\right) t} x_{0}(t) d t \\
& +2 \lambda_{L} e^{2\left(\lambda_{L}-\lambda_{H}\right) t_{0}} \int_{0}^{\infty} \int_{\tau_{1}}^{\infty} e^{-\gamma(t)} e^{-\lambda_{L}\left(t+\tau_{1}\right)}\left(\left(\lambda_{L}-\lambda_{H}\right)\left(t+\tau_{1}-2 t_{0}\right)+1\right) x_{1}\left(\tau_{1}, t\right) d t d \tau_{1}
\end{aligned}
$$

We can rearrange (39) to get

$$
\frac{1}{a_{0}+c}\left[\int_{0}^{\infty} t e^{-\left(\gamma+2 \lambda_{L}\right) t} x_{0}(t) d t+2 \lambda_{L} \int_{0}^{\infty} \int_{\tau_{1}}^{\infty} e^{-\gamma(t)} e^{-\lambda_{L}\left(t+\tau_{1}\right)} \frac{t+\tau_{1}}{2} x_{1}\left(\tau_{1}, t\right) d t d \tau_{1}\right] \geq t_{0}
$$

Also note that for $t \in\left[\tau_{1}, \infty\right)$ we have $t+\tau_{1} \leq 2 t$ so inequality (40) implies

$$
\frac{1}{a_{0}+c}\left[\int_{0}^{\infty} t e^{-\left(\gamma+2 \lambda_{L}\right) t} x_{0}(t) d t+2 \lambda_{L} \int_{0}^{\infty} \int_{\tau_{1}}^{\infty} t e^{-\gamma(t)} e^{-\lambda_{L}\left(t+\tau_{1}\right)} x_{1}\left(\tau_{1}, t\right) d t d \tau_{1}\right] \geq t_{0}
$$

Now consider the cost of this contract to the investors. We have the following

$$
\int_{0}^{\infty} e^{-\left(r+2 \lambda_{L}\right) t} x_{0}(t) d t=\int_{0}^{\infty} e^{(\gamma-r) t} e^{-\left(\gamma+2 \lambda_{L}\right) t} x_{0}(t)
$$

But $e^{(\gamma-r) t}$ is convex in $t$ so $e^{(\gamma-r) t} \geq(\gamma-r) e^{(\gamma-r) t_{0}}\left(t-t_{0}\right)+e^{(\gamma-r) t_{0}}$ which together with (42) implies that

$$
\int_{0}^{\infty} e^{-\left(r+2 \lambda_{L}\right) t} x_{0}(t) d t \geq e^{(\gamma-r) t_{0}} \int_{0}^{\infty}\left((\gamma-r)\left(t-t_{0}\right)+1\right) e^{-\left(\gamma+\lambda_{L}\right) t} x_{0}(t) d t
$$


Next we have

$$
\int_{0}^{\infty} \lambda_{L} e^{-\lambda_{L} \tau_{1}} \int_{\tau_{1}}^{\infty} e^{-\left(r+\lambda_{L}\right) t} x_{1}\left(\tau_{1}, t\right) d t d \tau_{1}=\int_{0}^{\infty} \lambda_{L} e^{-\lambda_{L} \tau_{1}} \int_{\tau_{1}}^{\infty} e^{(\gamma-r) t} e^{-\left(\gamma+\lambda_{L}\right) t} x_{1}\left(\tau_{1}, t\right) d t d \tau_{1}
$$

So by the same argument given above we have

$$
\begin{array}{r}
\int_{0}^{\infty} \lambda_{L} e^{-\lambda_{L} \tau_{1}} \int_{\tau_{1}}^{\infty} e^{-\left(r+\lambda_{L}\right) t} x_{1}\left(\tau_{1}, t\right) d t d \tau_{1} \\
e^{(\gamma-r) t_{0}} \int_{0}^{\infty} \lambda_{L} e^{-\lambda_{L} \tau_{1}} \int_{\tau_{1}}^{\infty} e^{-\left(\gamma+\lambda_{L}\right) t}\left((\gamma-r)\left(t-t_{0}\right)+1\right) x_{1}\left(\tau_{1}, t\right) d t d \tau_{1}
\end{array}
$$

We can combine inequalities (10), (41), (43) and (45) to get

$$
\int_{0}^{\infty} e^{-\left(r+2 \lambda_{L}\right) t} x_{0}(t) d t+2 \int_{0}^{\infty} \lambda_{L} e^{-\lambda_{L} \tau_{1}} \int_{\tau_{1}}^{\infty} e^{-\left(r+\lambda_{L}\right) t} x_{1}\left(\tau_{1}, t\right) d t d \tau_{1} \geq e^{-(\gamma-r) t_{0}}\left(a_{0}+c\right)
$$

but $e^{-(\gamma-r) t_{0}}\left(a_{0}+c\right)$ is the cost to the investors of the proposed contract. So we have shown that the proposed contract costs less (or the same) to the investors than any alternative contract that satisfies (10) and (11), hence the proposed contract is optimal.

Proof of Proposition 2 Consider an arbitrary incentive compatible contract $\left(x_{0}, a^{d}(t), \hat{a}^{d}(t)\right)$ and let

$$
K_{2}(t)=\frac{\hat{a}^{d}(t)}{a^{d}(t)} e^{-K_{1} t}
$$

where

$$
K_{1}=\frac{\left((\gamma-r)+2\left(\lambda_{H}-\lambda_{L}\right)\right)\left(\lambda_{H}-\lambda_{L}\right)}{(\gamma-r)+\left(\lambda_{H}-\lambda_{L}\right)}
$$

Define

$$
K_{2}^{*}=\frac{\int_{0}^{\infty} e^{-\left(\gamma+2 \lambda_{H}\right) t} \hat{a}^{d}(t) d t}{\int_{0}^{\infty} e^{-\left(\gamma+2 \lambda_{H}\right) t} e^{K_{1} t} a^{d}(t) d t} .
$$

Consider the new contract $\left(x_{0}, a^{d}(t), K_{2}^{*} e^{\left.K_{1} t\right)} a^{d}(t)\right)$ and note the new contract is incentive compatible by construction. We now show that it costs weakly less to the investors than 
the original contract. We have

$$
\begin{aligned}
\int_{0}^{\infty} e^{-\left(r+2 \lambda_{L}\right) t} b\left(a^{d}(t), \hat{a}^{d}(t), 1\right) d t= & \int_{0}^{\infty} e^{-\left(r+2 \lambda_{L}\right) t}\left(\frac{a^{d}(t)}{\hat{a}^{d}(t)}\right)^{\frac{\gamma-r}{\lambda_{H}-\lambda_{L}}} a^{d}(t) d t \\
= & \int_{0}^{\infty} e^{-\left(r+2 \lambda_{L}\right) t}\left(K_{2}(t) e^{K_{1} t}\right)^{-\frac{\gamma-r}{\lambda_{H}-\lambda_{L}}} a^{d}(t) d t \\
= & \int_{0}^{\infty} K_{2}(t)^{-\frac{\gamma-r}{\lambda_{H}-\lambda_{L}}} e^{-\left(r+2 \lambda_{L}\right) t} e^{-K_{1}\left(1+\frac{\gamma-r}{\lambda_{H}-\lambda_{L}}\right) t} e^{K_{1} t} a^{d}(t) d t \\
= & \int_{0}^{\infty} K_{2}(t)^{-\frac{\gamma-r}{\lambda_{H}-\lambda_{L}}} e^{-\left(\gamma+2 \lambda_{H}\right) t} e^{K_{1} t} a^{d}(t) d t \\
\geq & -\frac{\gamma-r}{\lambda_{H}-\lambda_{L}}\left(K_{2}^{*}\right)^{-\frac{\gamma-r}{\lambda_{H}-\lambda_{L}}-1} \int_{0}^{\infty}\left(K_{2}(t)-K_{2}^{*}\right) e^{-\left(\gamma+2 \lambda_{H}\right) t} e^{K_{1} t} a^{d}(t) d t \\
& +\int_{0}^{\infty}\left(K_{2}^{*}\right)^{-\frac{\gamma-r}{\lambda_{H}-\lambda_{L}}} e^{-\left(\gamma+2 \lambda_{H}\right) t} e^{K_{1} t} a^{d}(t) d t
\end{aligned}
$$

Observe that

$$
\int_{0}^{\infty}\left(K_{2}(t)-K_{2}^{*}\right) e^{-\left(\gamma+2 \lambda_{H}\right) t} e^{K_{1} t} a^{d}(t) d t=0
$$

by construction. Thus we have

$$
\begin{aligned}
\int_{0}^{\infty} e^{-\left(r+2 \lambda_{L}\right) t} b\left(a^{d}(t), \hat{a}^{d}(t), 1\right) d t & \geq \int_{0}^{\infty}\left(K_{2}^{*}\right)^{-\frac{\gamma-r}{\lambda_{H}-\lambda_{L}}} e^{-\left(\gamma+2 \lambda_{H}\right) t} e^{K_{1} t} a^{d}(t) d t \\
& =\int_{0}^{\infty} e^{-\left(r+2 \lambda_{L}\right) t}\left(K_{2}^{*} e^{K_{1} t}\right)^{-\frac{\gamma-r}{\lambda_{H}-\lambda_{L}}} a^{d}(t) d t \\
& =\int_{0}^{\infty} e^{-\left(r+2 \lambda_{L}\right) t} b\left(a^{d}(t), K_{2}^{*} e^{K_{1} t} a^{d}(t), 1\right) d t
\end{aligned}
$$

which means that the proposed contract costs weakly less than the original contract.

\section{References}

Ashcraft, A.B., A., and T. Schuermann, 2009, "Understanding the Securitization of Subprime Mortgage Credit," Working Paper.

Axelson, U., 2007, "Security Design with Investor Private Information," The Journal of Finance, 62(6), 2587-2632.

Boot, A., and A. Thakor, 1993, "Security Design," Journal of Finance, 48, 1349-1378. 
DeMarzo, P., 2005, "The Pooling and Tranching of Securities: A Model of Informed Intermediation," Review of Financial Studies, 18(1), 1-35.

DeMarzo, P., and D. Duffie, 1999, "A Liquidity Based Model of Security Design," Econometrica, 67, 65-99.

Glaeser, E., and H. Kallal, 1997, "Thin Markets, Asymmetric Information, and MortgageBacked Securities," Journal of Financial Intermediation, 6(1), 64-86.

Keys, B., T. Mukherjee, A. Seru, and V. Vig, 2008, "Did Securitization Lead to Lax Screening? Evidence from Subprime Loans 2001-2006," Working Paper.

Leland, H., and D. Pyle, 1977, "Informational Asymmetries, Financial Structure, and Financial Intermediation," Journal of Finance, 32(2), 371-387.

Mian, A., and A. Sufi, 2009, "The Consequences of Mortgage Credit Expansion: Evidence from the 2007 Mortgage Default Crisis," Quarterly Journal of Economics, Forthcoming.

Myers, S., and N. Majluf, 1984, "Corporate financing and investment decisions when firms have information that investors do not," Journal of Financial Economics, 13(2), 187-221.

Nachman, D., and T. Noe, 1994, "Optimal design of securities under asymmetric information," Review of Financial Studies, 7(1), 1-44.

Riddiough, T., 1997, "Optimal Design and Governance of Asset-Backed Securities," Journal of Financial Intermediation, 6(2), 121-152. 